\title{
ANALYSIS OF STUDENTS’ ACADEMIC PERFORMANCE AND PROGRESSION (USING MARKOV CHAIN APPROACH)
}

\author{
Murtala Adam Muhammad \\ Department of Statistics \\ Kano University of Science and \\ Technology, Kano, Nigeria.
}

\author{
Jamilu Yunusa Falgore \\ Department of Statistics \\ Ahmadu Bello University, Zaria \\ Nigeria.
}

\author{
Usman Hashim Sani \\ Department of Statistics \\ Kano State Polytechnics
}

\begin{abstract}
This paper studies the pattern of students' enrolment and their academic performance in the department of Statistics Ahmadu Bello University, Zaria. In this paper, a stochastic model for estimation was developed; the study programme was modeled by a finite Markov chain with 4 transient and two absorbing states. The probability transition matrix was constructed. The students' progression towards the next stage of the study programme was estimated, the expected time that a student spends at a particular stage as well as the expected duration of the study is determined. The probation, withdrawal and graduation probabilities were also obtained. The data was analyzed using R-Software.
\end{abstract}

Keywords - Enrolment, Markov Chain, Fundamental matrix, Probability of absorption and Study Programme

\section{INTRODUCTION}

Accessing students' academic performance is one of the important task for any educational system. A students' performance is measured by their academic strength, for example, a student may start from 100 level with CGPA $<1.5$ at the end of second semester, a Probation warning will be given to him and if the student did not improve next session the system automatically withdraws the student.

In probability theory, a stochastic or random process is a mathematical object usually defines as a collection of random variables. The random variables are associated with or indexed by a set of numbers usually viewed as point in time. Markov process can also be defined as a stochastic process (random process) indexed by time and with the property that the future is independent of the past, given the present. A discrete-time Markov chain is a stochastic process which is the simplest generalization of a sequence of independent random variables. A Markov chain is a random sequence in which the dependency of the successive events goes back only one unit in time [1]. Markov Chain Application has advance tremendously in various branches of natural science, engineering and medical science it also useful in the development of a model to study the movement of students' in higher institution. A lot of study is already been done in this area and are proven to be beneficial. [2] have applied the Markov chain to analyze and predict the mathematical achievement gap between African American and white American students. [3] have presented the Markov chain model of students' progress throughout the particular course. [4] who used the theory of Non-Homogeneous Markov Systems (NHMS) with fuzzy states for describing students' educational progress in Greek Universities. [5] used the application of in out-put models to project enrollment for and award of bachelor degree in Australian university universities. [6] used a version of this model to look at higher education in Australian. [7]; [8]; [9]; [10]; [11]; [12]; [13]; [14], modelled the students' progression and their performance during higher education study using an absorbing Markov chain

\section{METHODOLOGY}

The model for analysis of students' performance and academic progression is based on theory of absorbing Markov chain. The general form of the probability transition matrix of absorbing Markov chain with $\mathrm{r}$ absorbing and $\mathrm{t}$ transient states given in a canonical form as:

$$
P=\left(\begin{array}{cc}
Q & R \\
O & I
\end{array}\right)
$$

Where

$Q=t \times t$ Matrix expressing transition between transient

states. 


\section{International Journal of Engineering Applied Sciences and Technology, 2019 \\ Vol. 4, Issue 7, ISSN No. 2455-2143, Pages 187-193 \\ Published Online November 2019 in IJEAST (http://www.ijeast.com)}

$R=t \times r$ Matrix expressing transition from the transient state

to the absorbing state.

$0=r \times t$ Zero Matrix

$I=r \times r$ Identity matrix

We say such a transition matrix is in canonical form

\section{A. Fundamental Matrix}

For an absorbing Markov chain $P$, the matrix $M=(I-Q)^{-1}$

is called the fundamental for $P$. The entry $n_{\mathrm{ij} j}$ of matrix $M$

gives the expected number of time the process is in the transient state $\bar{j}$ if it started in the transient state $i$.

$M=(I-Q)^{-1}$

Where $I$ denote the identity matrix size $t \times t$ (unlike the size in

(1)) which is $r \times r$.

\section{B. Time of Absorption}

Let $\mu_{i}$ be the expected number of steps before the Markov

chain is absorbed into one of the absorbing state when it started in the transient state $\bar{i}$ and let $\mu$ be the column vector

whose $i^{\text {th }}$ entry is $\mu_{i}$ then

$\mu=M C$

Where $M$ is the fundamental matrix and $C$ is a column vector all of whose entries are 1's

\section{Absorption Probability}

Let $b_{i j}$ be the probability that an absorbing markov chain will be absorbed in the absorbing state $j$ if it starts in the transient state $i$. Let $B$ be the matrix with entries $b_{i j}$, then $B$ is a $t \times t$ matrix calculated as:
$B=M R$

Where

$M$ Is the Fundamental Matrix

$R$ Is the sub matrix from the transition matrix

\section{MODEL}

For a student to complete bachelor degree in statistics at Ahmadu Bello University, Zaria, he/she has to spend minimum of four years. There for to model the student academic progress we will define the following states:

- $\quad$ 1Level - the student is registered in the first year of the study programme

- 2 Level - the student is registered in the second year of the study programme

- 3 Level - the student is in the third year of the study programme

- 4 Level - the student is in the final year of the study programme

- W- The student has been withdrawn from the study programme

- G- The student graduated and completed the program effectively

To develop the model, the following assumption are considered:

- Students who is currently in the first year, second year and third year can either progress to next stage or repeat a year and stay at the same stage.

- Students who is currently in the fourth year can either repeat the same stage or finish the study

- Student who has been withdrawn will never finish his/her programme.

- Student who has graduated and successfully finished his/her programme will not apply for same programme again.

The state transition diagram of the student academic progression is illustrated below: 


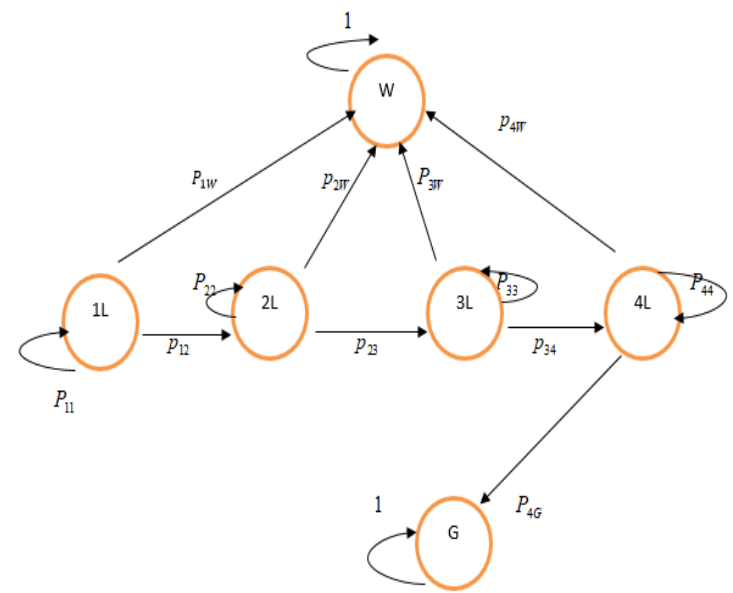

Fig. 1: State transition diagram for students' academic progression.

The Probability transition matrix describing the programme of student from the first study year towards graduation is:

\section{A. Estimation of transition probabiliy matrix}

From the table above, our one step transition probability matrix is as follows:

$$
n_{i j}=\left[\begin{array}{ccccccc} 
& 1 L & 2 L & 3 L & 4 L & W & G \\
1 L & 455 & 213 & 0 & 0 & 56 & 0 \\
2 L & 0 & 422 & 195 & 0 & 32 & 0 \\
3 L & 0 & 0 & 400 & 207 & 17 & 0 \\
4 L & 0 & 0 & 0 & 225 & 15 & 360 \\
W & 0 & 0 & 0 & 0 & 120 & 0 \\
G & 0 & 0 & 0 & 0 & 0 & 360
\end{array}\right]
$$

In obtaining the transition probability matrix, the frequency in each row is divided by its respective rows total. The transition probability matrix obtained is in canonical form. The canonical matrix reveals the probability of a student remaining in an academic state, as well the probability of moving to the next academic state.

$$
P_{i j}=\left[\begin{array}{cccccc}
0.6285 & 0.2942 & 0 & 0 & 0.0773 & 0 \\
0 & 0.6502 & 0.3005 & 0 & 0.0493 & 0 \\
0 & 0 & 0.6410 & 0.3317 & 0.0272 & 0 \\
0 & 0 & 0 & 0.375 & 0.025 & 0.6 \\
0 & 0 & 0 & 0 & 1 & 0 \\
0 & 0 & 0 & 0 & 0 & 1
\end{array}\right]
$$

The one step probability matrix $P_{\mathrm{i} \tilde{j}}$ above can be decompose into transient state $(\mathrm{Q})$ absorbing state $(\mathrm{R})$, identity matrix and zero matrix respectively

$$
Q=\left[\begin{array}{cccc}
0.6285 & 0.2942 & 0 & 0 \\
0 & 0.6502 & 0.3005 & 0 \\
0 & 0 & 0.6410 & 0.3317 \\
0 & 0 & 0 & 0.375
\end{array}\right]
$$

The table below shows the summary of the students' enrolment and their performances for 10 years.

\begin{tabular}{|l|l|l|l|l|}
\hline & $1^{\mathrm{ST}}$ Year & $2^{\mathrm{ND}}$ Year & $3^{\mathrm{RD}}$ Year & $4^{\mathrm{TH}}$ Year \\
\hline P & 213 & 195 & 207 & 0 \\
\hline R & 455 & 422 & 400 & 225 \\
\hline W & 56 & 32 & 17 & 15 \\
\hline G & 0 & 0 & 0 & 0 \\
\hline
\end{tabular}

Table-1 Summary result 
Published Online November 2019 in IJEAST (http://www.ijeast.com)

$R=\left[\begin{array}{cc}W & G \\ 0.073 & 0 \\ 0.0493 & 0 \\ 0.0272 & 0 \\ 0.0250 & 0.60\end{array}\right]$

$$
I=\left[\begin{array}{ll}
1 & 0 \\
0 & 1
\end{array}\right] \quad 0=\left[\begin{array}{llllllll}
0 & 0 & 0 & 0 & 0 & 0 & 0 & 0 \\
0 & 0 & 0 & 0 & 0 & 0 & 0 & 0
\end{array}\right]
$$

\section{B. Calculating The Entries of Fundamental Matrix M}

The fundamental matrix can be calculated as $M=(I-Q)^{-1}$

with the use of R- Software we were able to get the fundamental matrix $\mathrm{M}$

1

$M=\left[\begin{array}{cccc}2.6911 & 2.2639 & 1.8950 & 1.0057 \\ 0 & 2.8588 & 2.3929 & 1.2700 \\ 0 & 0 & 2.7855 & 1.4783 \\ 0 & 0 & 0 & 1.60\end{array}\right]$

From the above matrix it can be seen that during the enrolment in the study programme, it is expected that the student will spend 2.6911 academic year for the first year, 2.2639 academic year for the second year, 1.8950 academic year for the third year and 1.0057 academic year for the fourth year.

\section{Expected Time Untill Absorption(Withdraw or Graduation)}

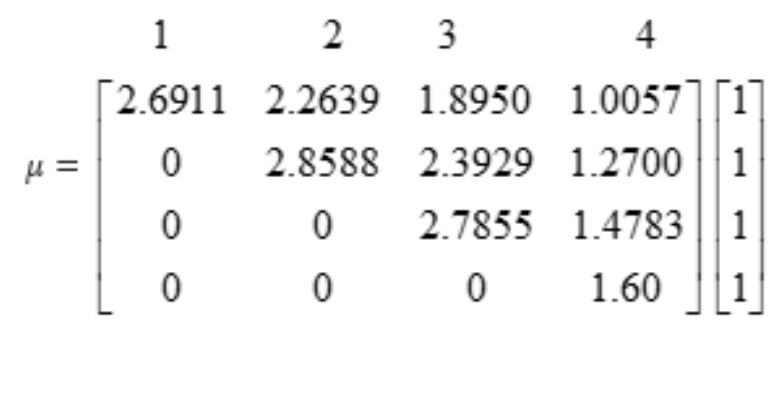

$$
\mu=\left[\begin{array}{c}
7.8695 \\
6.5217 \\
4.2638 \\
1.6
\end{array}\right]
$$

Result in the column vector is the expected time until absorption (Graduation or withdraw) from a given transient state.

\section{Probability of Absorption(Withdraw or Graduation)}

The probability that the process will enter the $\mathrm{j}^{\text {th }}$ absorbing state if it starts in the $\mathrm{i}^{\text {th }}$ transient state is called the probability of absorption. It is given as $B=M R$

$$
B=\left[\begin{array}{cc}
W & G \\
0.3991 & 0.6117 \\
0.2378 & 0.762 \\
0.1127 & 0.8870 \\
0.04 & 0.96
\end{array}\right]
$$

From above matrix it can be seen that the probability of graduation increases with the student progression over the study stages and also the probability of withdrawal decreases.

E. Forcasting the Future Performance of the Students 


$$
\text { for } n=1
$$

$1 L$
$2 L$
$3 L$
$4 L$$\left(\begin{array}{cccc}1 L & 2 L & 3 L & 4 L \\ 0.6285 & 0.2942 & 0 & 0 \\ 0 & 0.6502 & 0.3005 & 0 \\ 0 & 0 & 0.6410 & 0 \\ 0 & 0 & 0 & 0.375\end{array}\right)$

for $n=2$

\begin{tabular}{l|c}
$1 L$ \\
$1 L$ & 0.3950 \\
$2 L$ & 0 \\
$3 L$ & 0 \\
$4 L$ & 0
\end{tabular}

$\begin{array}{cl}2 & L \\ 0.3 & 736 \\ 0.42 & 228 \\ 0 & \\ 0 & \end{array}$

$\left.\begin{array}{cc}3 L & 4 L \\ 0.0884 & 0 \\ 0.3880 & 0.0997 \\ 0.4109 & 0.3370 \\ 0 & 0.1406\end{array}\right)$

for $n=3$

\begin{tabular}{l|c}
$1 L$ \\
$1 L$ \\
$2 L$ \\
$3 L$ \\
$4 L$
\end{tabular}$\quad \begin{gathered}0.2483 \\
0 \\
0\end{gathered}$

$2 L$
0.3608
0.2749
0
0

$$
3 L
$$$$
0.1697
$$$$
4 L
$$$$
0.3758
$$$$
0.0293
$$$$
0.2634
$$$$
0.1661
$$$$
0
$$$$
0.2627
$$$$
0.5273 \text { ) }
$$

$$
\text { for } n=4
$$

\begin{tabular}{c|c}
$1 L$ & $1 L$ \\
$2 L$ & 0.1560 \\
$3 L$ & 0 \\
$4 L$ & 0 \\
0
\end{tabular}

$2 L$
0.3076
0.1787
0
0

$3 L$
0.2172
0.3235
0.1688
0

$\left.\begin{array}{c}4 L \\ 0.067 \\ 0.1869 \\ 0.1859 \\ 0.0198\end{array}\right)$

\section{F. Discussion of Result}

From the transition probability it was discovered that rate of withdrawal decreases as the student progress to the highest level while the rate of graduation increases. The performance of student improve over time as they move from one state to another. It is expected that the student will spend 2.6911 academic year for the first year, 2.2639 academic year for the second year, 1.8950 academic year for the third year and 1.0057 academic year for the fourth year.

\section{CONCLUSION}

In this paper a Markov chain model for Statistics student in Ahmadu Bello University, Zaria for examining the flow of undergraduate student was develop. This model shows movement of student from one state to another throughout their tertiary institution, the model gives the average students that graduate, average time a student will stay and complete the course of study.

\section{A. Abbreviation}

The following abbreviations are used in this manuscript

P Promoted

R Repeat

W Withdraw

G Graduate

1L 100 Level

2L 200 Level

3L 300Level

4L 400Level

\section{B. Acknowledgement}

There is no complicit of interest between the three authors. There is no funding for the research.

\section{REFERENCE}

[1] Tijms, H.C. (2003). A first course in stochastic models. John Wiley and sons.

[2] Moody, V. R., \& DuClouy, K. K. (2014). Application of Markov Chains to Analyze and Predict the Mathematical Achievement Gap between African American and White American Students. Journal of Applied \& Computational Mathematics, 3, 161.

[3] Hlavatý, R., \& Dömeová, L. (2014). Students' Progress throughout Examination Process as a Markov Chain. International Education Studies, 7(12), 20-29.

[4] Symeonaki, M., \& Kalamatianou, A. (2011). Markov Systems with Fuzzy States for Describing Students' Educational Progress in Greek Universities. Isi, 1, 5956-5961.

[5] Gani, J. (1963). Formulae for projecting enrolments and degrees awarded in universities. Journal of the Royal Statistical Society: Series A (General), 126(3), 400-409.

[6] Poland, D., \& Scheraga, H. A. (1970). Theory of helix-coil transitions in biopolymers. 
[7] Adam, R. Y. (2015). An Application of Markov Modeling to the Student Flow in Higher Education in Sudan. International Journal of Science and Research, 4(2), 49-54.

[8] Adeleke, R. A., Oguntuase, K. A., \& Ogunsakin, R. E. (2014). Application of Markov Chain to the Assessment of Students' Admission and Academic Performance in Ekiti State University. International Journal of Scientific \& Technology Research, 3(7), 349-357.

[9] Al-Awadhi, S. A., \& Ahmed, M. A. (2002). Logistic models and a Markovian analysis for student attrition. Kuwait Journal of Science and Engineering, 29(2), 25-40.

[10] Konsowa, M., \& Al-awadhi, f.a.h.i.m. a. h. (2010). Hitting times and the speed of random walks on trees. No. Paper ID, 241.

[11] Al-Awadhi, S. A., \& Konsowa, M. (2007). An application of absorbing Markov analysis to the student flow in an academic institution. Kuwait J. Sci. Eng., 34(2A), 77-89. [12] Auwalu, A., Mohammed, L. B., \& Saliu, A. (2013). Application of Finite Markov Chain to a Model of Schooling. Journal of Education and Practice, 4(17), 1-10.

[13] Mashat, A. F., Ragab, A. H., \& Khedra, A. M. (2012). Decision support system based Markov model for performance evaluation of students flow in FCITKAU. Proceedings of the ICCIT, 409-414.

[14] Shah, C., \& Burke, G. (1999). An undergraduate student flow model: Australian higher education. Higher Education, 37(4), 359-375. 
International Journal of Engineering Applied Sciences and Technology, 2019 Vol. 4, Issue 7, ISSN No. 2455-2143, Pages 187-193

Published Online November 2019 in IJEAST (http://www.ijeast.com) 